\title{
.HIGH CHEST LEADS AND MINOR MYOCARDIAL INFARCTIONS
}

\author{
BY \\ HUGO ROESLER \\ From the Temple University Medical Center, Philadelphia, Pa., U.S.A. \\ Received November 24, 1958
}

Electrocardiographic studies in patients with either a suspected or clear-cut anginal history may reveal a wide variety of findings ranging from altogether normal or borderline normal through patterns compatible with so-called coronary insufficiency, anoxia, ischæmia, injury, to frank infarction. Abnormal findings may appear or may become more outspoken when a tracing is taken during an anginal seizure, whether it be spontaneous or induced.

This study is limited to electrocardiographic abnormalities of relatively minor degree, essentially affecting the $\mathrm{T}$ deflections only, that emphasize in particular the use of exploring chest leads at a higher level.

That the incidence of omissions and commissions in electrocardiographic interpretation is considerable, due to the widespread use of the method by inadequately trained, inadequately experienced, and uncritical physicians, is known. Some of what one may call finer diagnostic points may be overlooked by men otherwise competent in this field; this, as the author has repeatedly noted, refers to the abnormal findings described in this study.

It is usually the office patient with a suspected or clear-cut anginal history whose electrocardiogram is likely to reveal only minor changes, in contrast to that of the patient who, obviously ill, is admitted to the hospital and submitted to a study. All our patients, and they are described later in detail, were seen in the office except one: this one was referred, while in the hospital for electroshock therapy, for cardiac evaluation. None of the patients had had a heavy meal or a cold drink nor had any of them smoked just prior toithe examination. None had received digitalis, quinidine, or adrenaline. None had thyroid dysfunction or anæmia. Three were diabetic. Five were heavy tobacco smokers. None had suffered chest trauma; and none had experienced paroxysmal rapid heart action. One of the patients had a minor degree of aortic regurgitation and showed slight left ventricular hypertrophy. All the others showed normal heart size and sounds and rhythm. Only one exhibited a mild degree of diastolic hypertension. Except for one, a diabetic who also revealed evidence of occlusive arterial disease in the lower limbs, all had the anginal syndrome. One patient was seen but once, all others repeatedly, at intervals of from two weeks to eight years.

All electrocardiographic studies were done by the author personally. The high chest leads were taken at the level of the third rib. None of the tracings were obtained during an anginal seizure.

\section{CASE REPORTS}

Case 1. This 60-year-old man was a mild diabetic and a heavy cigar smoker. His father died suddenly in an attack of chest pain and his father's sister died with a stroke. For a period of six weeks before the examination, there occurred anginal distress, both at rest and with effort. Examination showed normal heart size and sounds, and low normal blood pressure. Cardiographic study. The heart was in the semihorizontal electrical position. There were no significant $Q$ deflections. $T 1$ was lower than $T 3, T$ in lead aVL was negative, $T$ in lead aVF was high; at the usual level of the chest leads $T$ was normal, at a higher level (here as well as in all subsequent cases level of the third rib), $T$ was of diminished voltage in leads 
V5 and V6. With respect to the chest leads abnormal findings were noted only at a higher level. The conclusion was high lateral wall lesion.

Case 2. This 42-year-old man was a mild diabetic, and his mother had had diabetes. Anginal distress on exertion was present for a period of two months before the first examination which showed the heart to be normal in size and sounds, while the blood pressure was normal. The findings were the same at the second examination. The cholesterol level was raised, the sedimentation rate was normal. Two cardiographic studies were done at an interval of seven weeks. The heart was in the semi-horizontal electrical position, QRS was 0.11 seconds wide, $Q$ deflections of small voltage and not exceeding 0.03 seconds in width were noted in leads I, aVL, V4, 5, 6; the intrinsicoid deflection in lead V6 measured $0.06 \mathrm{sec}$., T1 was lower than T3, T in aVL was negative, $\mathrm{T}$ in aVF was high; at the regular level of the chest leads, $\mathrm{T}$ was of lowered voltage in lead V4, at a higher level, $\mathrm{T}$ was negative in lead V1, plus-minus in leads V2, 3, 4, low and notched in lead V5. The findings were constant at both occasions. With respect to the chest leads, the higher level offered significantly more abnormal findings. It was concluded that there was a minor degree of intraventricular conduction disturbance and a predominantly high antero-lateral wall lesion.

Case 3. This 56-year-old man was a diabetic and a heavy cigarette smoker. His brother was a diabetic. The history was negative for angina. The first examination was done before an operation (laryngectomy) and showed normal heart size and sounds, and a slight elevation of the systolic blood pressure. The second examination five months later showed identical clinical findings. Two cardiographic studies were done five months apart. The heart was in a nearly intermediate electrical position, $\mathrm{T} 1$ was lower than $\mathrm{T} 3$, $\mathrm{T}$ in lead aVL was negative, $\mathrm{T}$ in lead $\mathrm{aVF}$ was high; at the regular level of the chest leads, $\mathrm{T}$ was low and notched in leads V4, 5; at a higher level, T was negative in leads V1, 2, 3, 4, and low and notched in lead V5. The findings were constant at both occasions. With respect to the chest leads, the higher level offered more significant abnormal findings. A diagnosis of high antero-septal wall lesion was made.

Case 4. This man was observed for a period of 8 years, from age 53 to 61. Rather mild exertional anginal distress occurred off and on and was always relieved by taking nitroglycerine. Examination showed normal heart size and sounds, and normal blood pressure. There was a normal cholesterol level and a normal sedimentation rate. Out of a number of cardiographic studies two are presented, six years apart (Fig. 1). The conclusion was that a predominantly high septal-lateral wall lesion had progressed slowly.

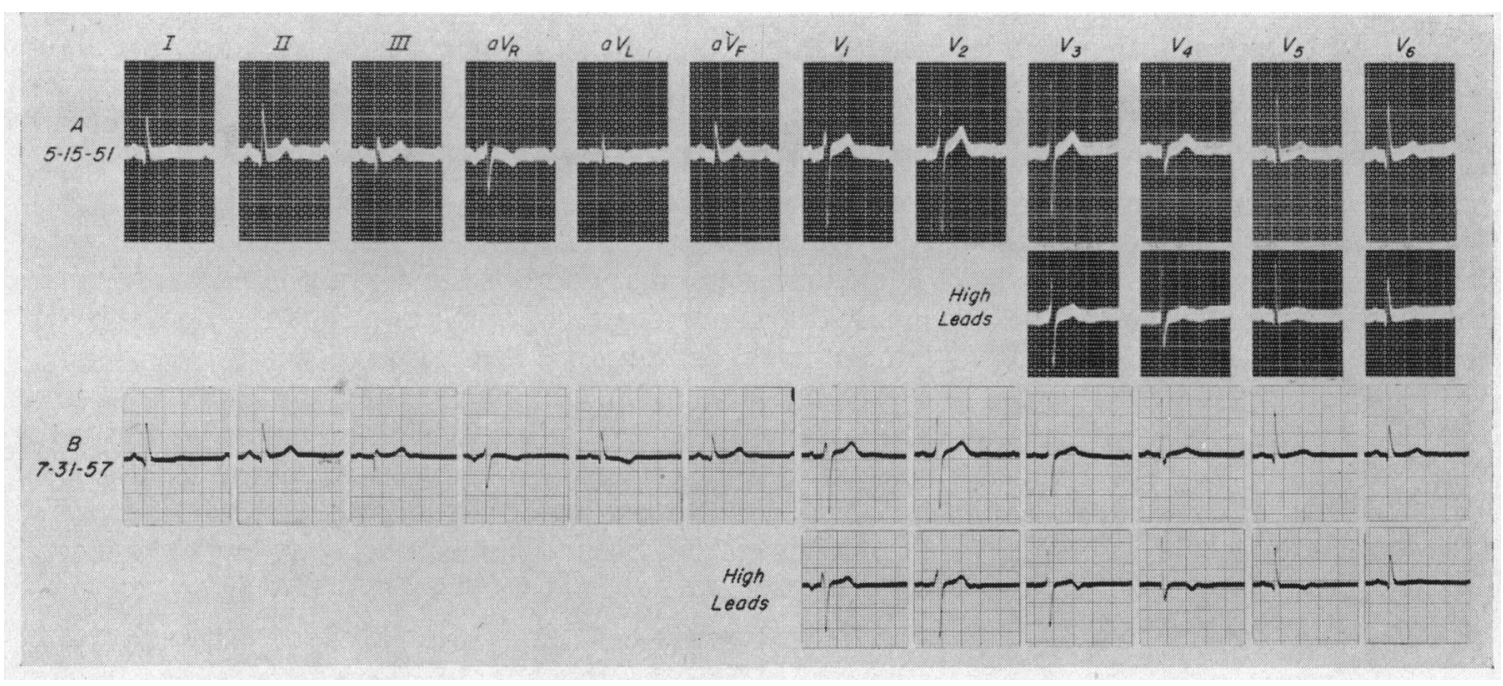

FIG. 1.-Case 4. The heart is in the electrical intermediate position; $Q$ deflections that are small and are of low voltage are noted in leads I, II, aVL, aVF, V4, 5, 6; T1 is lower than T3, T in lead aVL is negative, T in lead aVF is high. In graph $A$, at the regular level of the chest leads, $T$ is normal; at a higher level $T$ is of lowered voltage in leads $\mathrm{V} 3,4,5,6$; in graph $\mathrm{B}$, at the regular level, $\mathrm{T}$ shows diminished voltage in leads $V 3,4,5$, while at a higher level T shows a secondary negative dip in lead V2, negativity in leads V3, 4, 5, and is of low voltage in lead V6. The findings have changed from graph A to graph B, over a period of 6 years. In graph A the regular chest leads were normal, the high chest leads abnormal; in graph B the regular chest leads showed less significant alterations as compared with those obtained at a higher level. 
Case 5. This 60-year-old man was a heavy cigarette smoker. His blood pressure was normal. Two days prior to the first examination, there started a severe attack of anginal pain that was prolonged. Examination showed normal heart size, low intensity of heart sounds, low blood pressure, and low grade fever. The cholesterol level was raised and there was elevation of the sedimentation rate. A second examination was made two weeks later, the patient having rested and not having experienced any further anginal distress; the cardiac and blood pressure findings were the same. Two electrocardiograms were done two weeks apart (Fig. 2). A diagnosis of high lateral wall lesion was made.

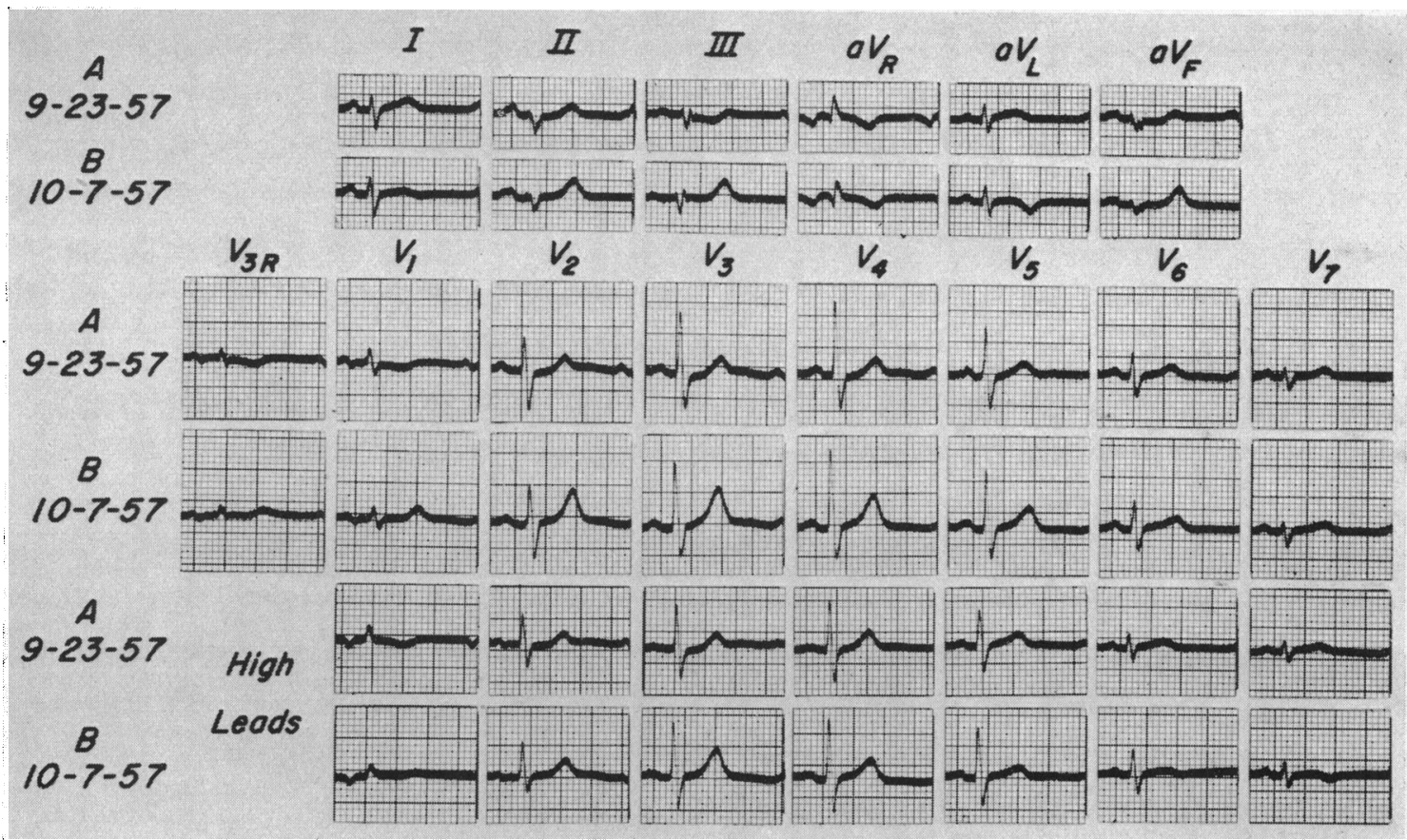

FIG. 2.-Case 5. The heart is in an indeterminate electrical position, and there is a minimal $Q$ deflection in lead aVL. There are $\mathbf{S}$ deflections across the præcordium and diminished voltage of the upward stroke on the left side; reciprocal S-T deviations are noted in limb and chest leads in graph A; in graph B, T1 is plus-minus, $\mathrm{T}$ in lead aVL is negative, $\mathrm{T}$ in lead aVF is high. In graph $\mathrm{A}, \mathrm{T}$ at the regular as well as at the higher level is not remarkable; in graph $B$ the $T$ voltage in the right præcordial leads at both regular and high level has increased, while at the higher level T has turned negative in leads V6, 7. Findings have changed from graph A to graph B, with the patient recovering from a myocardial infarction. The high chest leads render more information than those obtained at the regular level.

Case 6. This 50-year-old man used to be a heavy cigarette smoker. Sixteen months previously he had developed anginal pain, was in hospital for a period of 5 weeks, having serial electrocardiograms done, and this was followed by a rest period of $2 \frac{1}{2}$ months. Later on, mild angina occurred, chiefly on hurried walking. Several examinations in the course of $1 \frac{1}{2}$ years showed normal heart size and sounds, and a mild elevation of both systolic and diastolic blood pressure. The serum cholesterol level was normal; the sedimentation rate was initially normal but rose later when the anginal syndrome became worse and occurred at rest, necessitating rest in bed. Ultimately, the patient became free of angina. Out of a number of electrocardiograms, three are presented (Fig. 3). It was concluded that there was an area of fibrosis of posterodiaphragmatic location, and also development and regression of a predominantly high antero-lateral wall lesion.

Case 7. This 38-year-old-man was rejected by the army medical examiner 16 years previously because of the presence of a heart murmur. His effort capacity was excellent. He was a heavy cigarette smoker. Six days before the first examination, he developed anginal distress at rest and this recurred under resting conditions for the next several days. Examination revealed slight left ventricular hypertrophy, and a short diastolic aortic murmur. The systolic pressure was normal while the diastolic level was moderately lowered. 


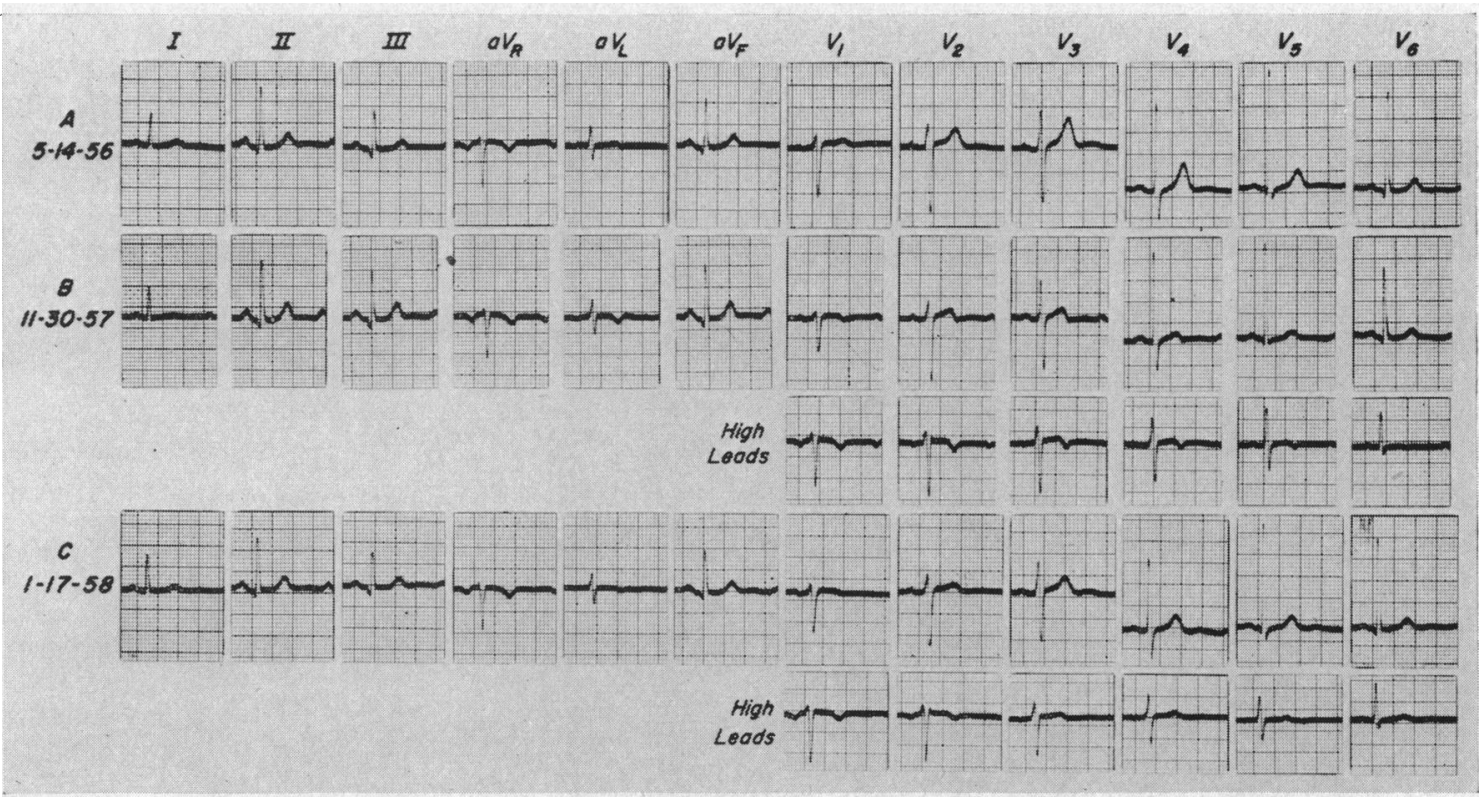

FIG. 3.-Case 6. The heart is in the semivertical electrical position; there are $Q$ deflections in leads II, III, aVF, of 0.03 to $0.04 \mathrm{sec}$. duration, and there are minimal $\mathrm{Q}$ deflections in the left præcordial leads (in the presence of rather high $\mathrm{R}$ deflections); the intrinsicoid deflection in leads II, III, aVF measures 0.04 to 0.05 sec. $\mathrm{T} 1$ is lower than T3, T in lead aVL is low and plus-minus to negative, $\mathrm{T}$ in Lead aVF is high. In graph A, at the regular level of the chest leads. $T$ is normal; in graph $B$, at the usual level of the chest leads, $T$ is negative in lead V1, positive and followed by a small secondary negative dip in leads $\mathrm{V} 2,3,4$, low positive in leads $\mathrm{V} 5,6$; at the higher level $\mathrm{T}$ is negative in leads $\mathrm{V} 1,2,3,4,5,6$. In graph $\mathrm{C}$, at the regular level of the chest leads, $\mathrm{T}$ is slightly negative in lead $\mathrm{V} 1$, low positive in lead $\mathrm{V} 2$, positive but of lower voltage than originally in the leads $\mathrm{V} 3,4,5,6$; at the higher level $\mathrm{T}$ is negative in leads $\mathrm{V} 1,2$, plus-minus in lead $\mathrm{V} 3$, low positive in leads $\mathrm{V} 4,5,6$. Findings have changed from graph $\mathrm{A}$ to graph $\mathrm{B}$ to graph $\mathrm{C}$, the abnormal findings being most marked in graph B at which time the anginal syndrome was at its worst. Chest leads taken at a higher level offered significantly more information.

The serum cholesterol level was raised, the sedimentation rate was slightly raised, and the blood serologic study was non-reactive. On rest and discontinuation of smoking, the angina diminished greatly but it subsequently returned and was frequent under resting conditions. Ultimately the patient was free of angina and returned to work. Three cardiograms were made (Fig. 4). The conclusion was that a predominantly antero-septal wall lesion had occurred.

Case 8. This 56-year-old woman suffered from recurrent depressive moods, she also was the bearer of a painful, stiff shoulder. She was studied prior to treatment by electro-shock theraphy. On examination, she showed normal heart size and sounds, and normal blood pressure. The sedimentation rate was slightly elevated. A few hours following the shock treatment, she developed painful distress to the left of the sternum and over the left chest. Subsequently, the chest discomfort disappeared, and there was no walking angina. Three electrocardiograms were done (Fig. 5), the first before shock treatment and the two others subsequently. A final diagnosis of transient high antero-lateral wall lesion was arrived at.

Case 9. This patient showed in the cardiogram more advanced changes as compared with the preceding cases, and hence is not quite within the scope of this paper, but is presented because of certain interesting features. He was a 49-year-old man and had a normal blood pressure. His illness had started $3 \frac{1}{2}$ months previously with effort angina and he developed a more severe attack with shock one month later, and subsequently rested in bed. On examination, the heart was normal in size and sounds; the blood pressure was normal. The cholesterol level was slightly elevated, the sedimentation rate was normal. Subsequently, the patient resumed work being free of angina, and a follow-up examination revealed nothing of significance. Two cardiograms were done 17 months apart: The heart was in nearly an intermediate electrical position, there were significant $Q$ deflections in leads $I$, and $\mathrm{aVL}$, and at the regular level of chest leads there were small Q deflections over the left side; in the earlier record, at the regular level of chest leads, 


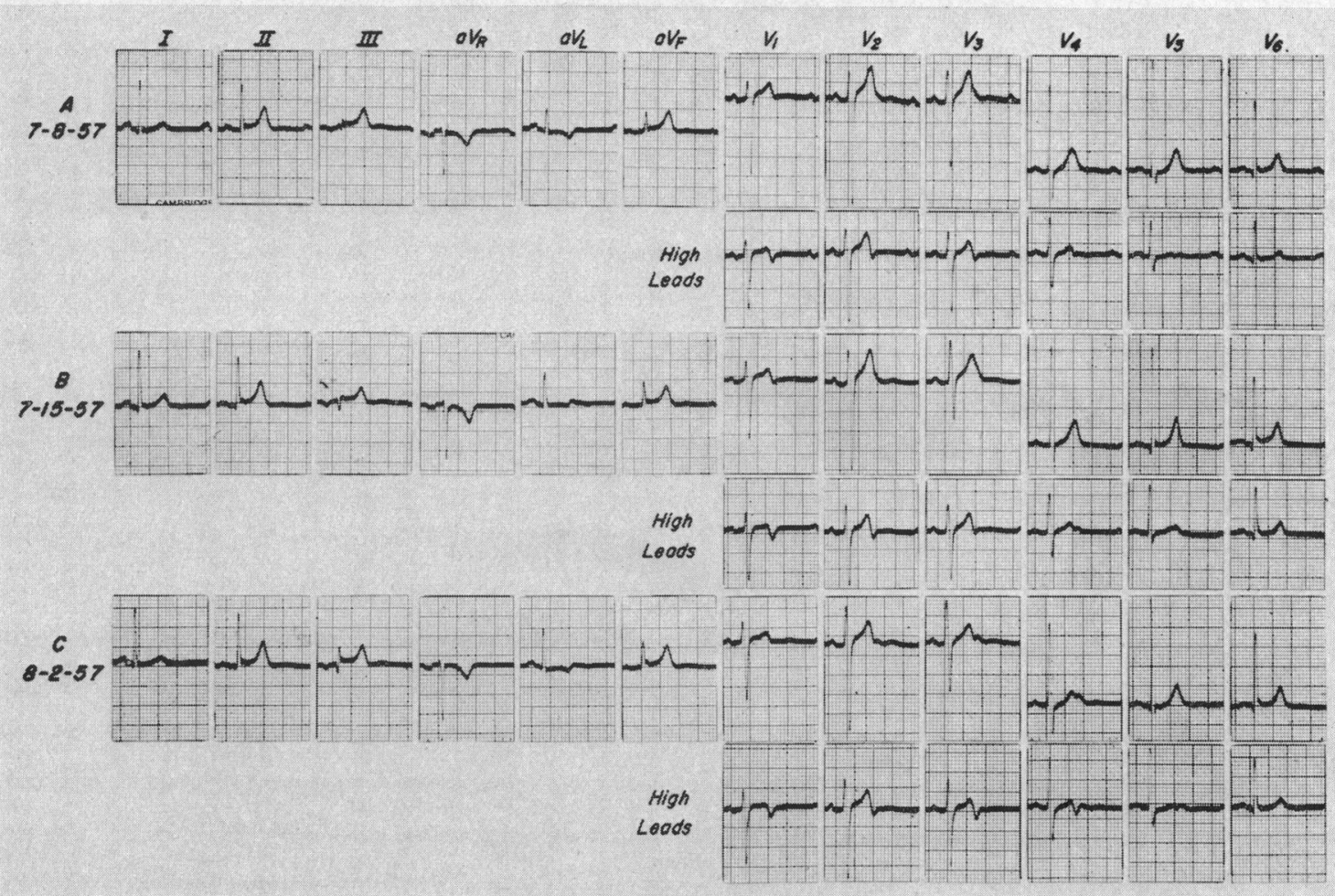

Fig. 4.-Case 7. The $P$ deflection is notched (as a part of old rheumatic heart disease); the heart is in the intermediate electrical position, QRS in the chest leads suggests the presence of left ventricular hypertrophy, and there are persistent slight S-T elevations in leads III, aVF, and in V6. In graphs B and C, T1 is lower than T3 and $\mathrm{T}$ in lead aVF is high; in graph $\mathrm{A}$, at the regular level of chest leads, $\mathrm{T}$ is normal, while at the higher level, $\mathrm{T}$ is plus-minus in leads $\mathrm{V} 1,2,3$, positive with a secondary negative dip in lead $\mathrm{V} 4$, and low and notched in lead V5. In graph B, at the regular level of the chest leads, T is normal (perhaps with the exception of a secondary negative dip in lead V1); at the higher level, $\mathrm{T}$ is negative in lead V1, plus-minus in leads V2, 3, low and notched in lead V4, and low positive in lead V5. In graph C, at the regular level of chest leads, T is notched in leads V2, 3, 4; at the higher level, $\mathrm{T}$ is negative in lead V1, plus-minus in leads V2, 3, 4, and low and notched in lead V5. Findings have changed from graph A to graph B to graph $\mathrm{C}$, the abnormal findings being most marked in graph $\mathrm{C}$, at which time the anginal syndrome was worse. In graph $\mathrm{A}$, chest leads at a usual level offered no abnormal findings; graphs $\mathrm{B}$ and $\mathrm{C}$ were more informative than leads taken at a higher level.

the voltage of $R$ was less than in the later tracing, and the same held true for leads $V 4,5,6$, at a higher level, in both records the voltage of $\mathrm{R}$ at the higher level diminishing from leads V1 to V2 to V3; furthermore, a QS deflection in lead V4 in the earlier cardiogram had practically disappeared in the later one; T1 was lower than T3, T was high in lead aVF; in the first cardiogram, $T$ at the regular level of chest leads was of low voltage in leads V5, 6, and it was negative at a higher level across the præcordium; in the second record at the regular level of chest leads, $\mathrm{T}$ was normal, at the higher level $\mathrm{T}$ was plus-minus in leads $\mathrm{V} 1$, 2,3 , and positive in leads $\mathrm{V} 4,5,6$. These changing patterns showed regression of the lesion. At both occasions the high chest leads revealed decidedly more information. The diagnosis was antero-lateral wall infarction, more so in high position, partially transmural, with partial recovery.

\section{Discussion}

Inversion of $T$ Deflections, associated with a Normal Initial Deflection. While, generally speaking, inversion of the $\mathrm{T}$ deflections is a non-specific finding, it becomes diagnostically very significant when there is a history of angina, past or present, particularly after pericarditis and electrolyte imbalance have been ruled out. Such a finding is frequently interpreted as "ischæmia", the 


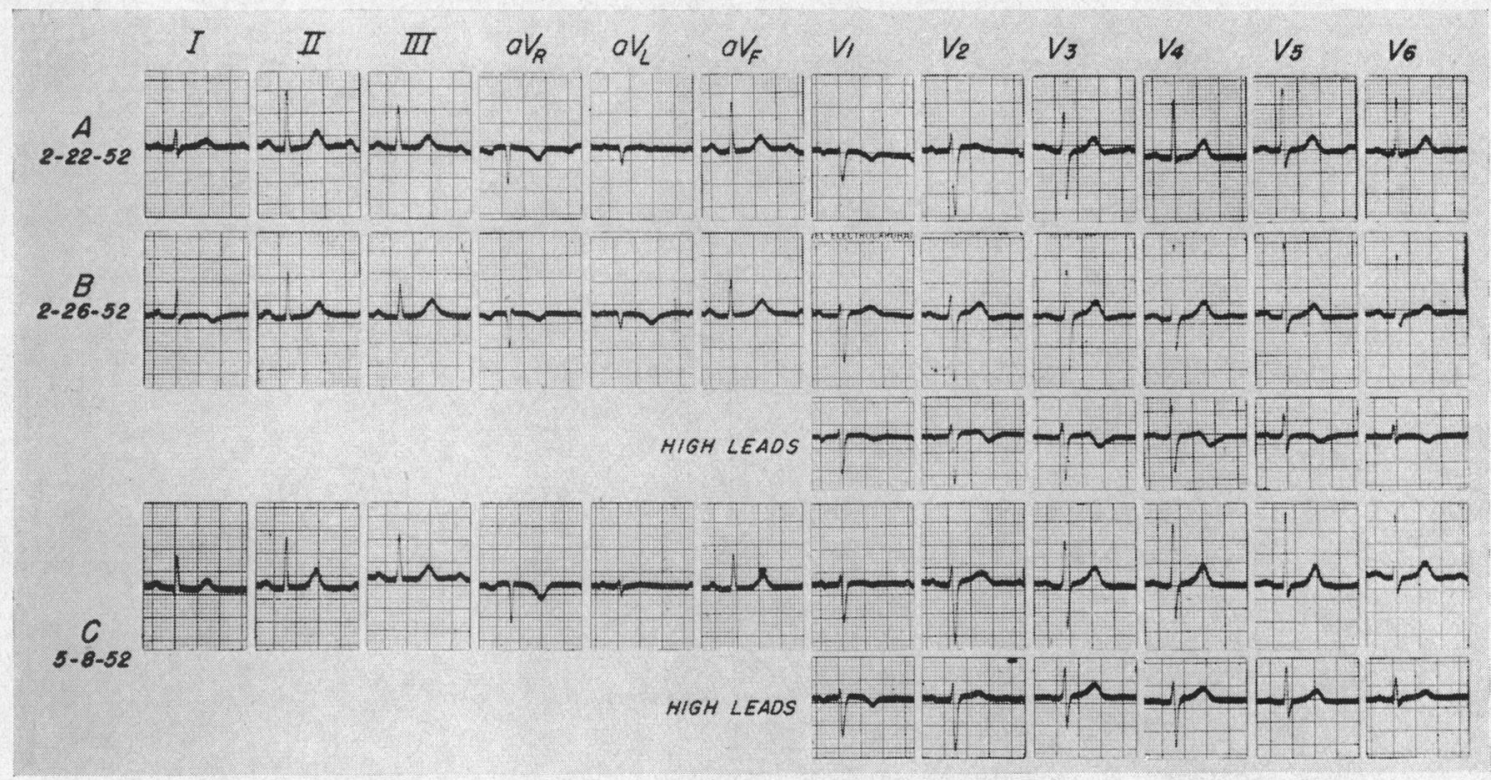

FIG. 5.-Case 8. The heart is in an electrical vertical position. In graph A, T1 is lower than T3, T is slightly negative in lead aVL, and T is high in lead aVF; at the regular level of chest leads, $T$ is negative in lead V1, notched in lead V2, and normal in leads V3, 4, 5, 6. In graph B, T is negative in leads I and aVL; at the regular level of chest leads, $T$ has turned positive in leads V1, 2, while the voltage has slightly dropped in leads V5, 6 ; at the higher level $\mathrm{T}$ is negative across the whole præcordium. In graph $\mathrm{C}, \mathrm{T}$ is now near the baseline in lead aVL; at the regular level of chest leads, $T$ is normal across the præcordium and also at the higher level (perhaps with exception of lead V1). Findings have changed from graph A to graph B (taken when there had been chest distress following electro-shock therapy) and graph $C$. In graph B, when the regular chest leads fell within normal limits, the high chest leads were definitely abnormal.

implication often being that this is a reversible state (which pictorially it often is), and that, if there is present an "organic" lesion, it is of limited degree and extension. It is furthermore true that many of these patients reveal no electrocardiographic evidence of injury current, i.e. displacement and modification of the form of the S-T segments, even when the record is taken early. These abnormal $T$ deflections are often reversible, and the patients often show a benign clinical course, though recurrences will take place; they deserve careful clinical and cardiographic follow-up studies because progression to a more extensive lesion may occur. Recovery of the abnormal $\mathrm{T}$ wave pattern has been described by East and Oram (1948) and by Papp and Smith (1951). T deflection changes, in association with the anginal syndrome, have been attributed to a diffuse and intense cardiac ischæmia from interruption of the blood flow in the left coronary artery, this temporary interruption of the coronary blood stream being apparently explained by a spasm of an artery unaffected by material atherosclerosis (Evans, 1955). The number of anatomically verified cases is small but the available evidence points to the fact that these patients have permanent structural damage, narrowing and atherosclerosis of the coronary arteries, and small infarctions (Pruitt, Klakeg, and Chapin, 1955; Cutts, Merlino and Easton, 1957; Abrahams, 1957; Kubicek, 1958).

Of the first eight patients described in this study, none had Q deflections of a significant degree in the chest leads at either regular or high level; one of these (Case 6) had Q deflections in leads II, III, aVF, depicting an old postero-diaphragmatic lesion. The abnormal $\mathrm{T}$ deflections in the chest leads were either constant (Cases 2, 3), or regressive (Cases 6,8), or progressive (Cases 4, $5,7)$, one patient was seen only once (Case 1). In seven out of these eight, an anginal history was present. Case 9, who also gave an anginal history, showed more advanced electrocardiographic alterations and revealed regressive changes with respect to both the initial and the final deflection.

High Chest Leads. While each chest lead depicts electrical changes produced in the heart as a 
whole, patterns obtained at the individual lead locations on the body surface depend upon their proximity to the heart and are influenced more by changes in this proximity than by those in distant parts of the heart. Rosenbaum et al. (1946) first pointed out that in instances of suspected infarction of the basal parts of the lateral wall of the left ventricle, the usual unipolar limb leads and the six standard præcordial leads failed to furnish unequivocal evidence of myocardial infarction, while unipolar leads from points on the anterolateral, lateral, and posterolateral aspects of the upper left thorax supplied electrocardiographic data of greater value. They recommended that such leads at a higher level be taken when the clinical history and lead I, or lead aVL, both suggest that myocardial infarction has occurred and the standard leads from the left side of the præcordium fail to display changes of the kind and magnitude expected. Their cases represent instances of fairly good-sized lesions, to judge by the presence of alterations in the initial complex ( $Q$ deflections), certainly in the high leads and sometimes, though to a lesser degree, in the leads taken at the usual level. The same consideration holds true for case reports in subsequent publications, such as by Alzamora and Mispireta (1948), Myers et al. (1948, 1949), and Reindell and Klepzig (1958). In this connection attention is directed to the fact that absence of $Q$ deflections depicting the epicardial aspect of the apical portion of the left ventricle may be noted despite the presence of an infarction (recent or old); namely when the left side of the apical portion of the septum is involved, resulting in a reversal of its activation to a right-to-left vector, in which case, however, high leads would disclose abnormal QS and QR complexes (Myers and Talmers, 1955; Burch and Ziskind, 1956).

That QRS abnormalities noted in the high chest leads, due to myocardial infarction, may disappear was pointed out by Benchimol et al. (1947), and is exemplified by our Case 9 .

Abnormal T deflections (either inverted or of the low-notched type) predominantly or exclusively occurring in the high chest leads, in conjunction with the anginal syndrome and due to myocardial lesion (infarction) have been described by Dressler and Roesler (1948), Mussafia and Comberiati (1950), and Schlant et al. (1954).

The positioning of these high exploring leads, as described by various authors, varies. In this study, the leads were taken at the level of the third rib.

A systematic study of high chest leads for normal persons was done by Massumi (in Prinzmetal et al. 1957); $\mathrm{Q}$ deflections were noted only in position V1 and in the midline in the first intercostal space, and in position $\mathrm{V} 1$ in the second intercostal space; $\mathrm{T}$ was invariably negative in position V1 in the first intercostal space, invariably positive in V4 of all three intercostal spaces, the intervening leads showing transitions between the two extremes; the initially positive $\mathrm{R}$ deflections were small on the right side and higher on the left side.

The Triad: T1 lower than T3, T negative in AVL and high in AVF, and T abnormal (negative, low, notched) in high chest leads. The pattern T1 lower than T3 as described by Dressler (1943), and Dressler and Roesler (1948), is frequently associated with myocardial infarction not of extensive degree, but is not specific since it is observed in patients with normal hearts that are vertical in position and in patients with pulmonary emphysema; vertical position favours transmission of cavity potential, therefore $\mathrm{T}$ in aVL is frequently negative and this leads to a low voltage $\mathrm{T}$ in $\mathrm{I}$. Subsequent studies along this line were made by Tourniaire et al. (1950), Peluffo (1951), Van Dooren and Boyadjian (1952), and Moll and v. Lutterotti (1952). The significance of a negative T in aVL greatly increases when the initial deflection in this lead is upright; it points to an abnormality in the anterolateral area, and, if nothing abnormal is noted in the conventional præcordial leads, it points to an abnormality at a level further craniad. Goldberger (1947) had stated that T1 will be less than T3 whenever T left arm is negative, and this is correct, but his statement that when this pattern occurs after anterior infarction, the multiple præcordial leads show typical patterns of anterior infarction is incorrect, as shown by Dressler and Roesler (1948) and by this study. When there is a basal lesion of the heart, usually antero-septal or antero-lateral in location, the negative potential of the left arm is greater than that of the right arm, $\mathrm{T}$ in aVL is negative, $\mathrm{T} 1$ is lower than $\mathrm{T} 3, \mathrm{~T}$ in aVF reciprocally is high, and yet the $\mathrm{T}$ deflections in the præcordial leads taken at the customary 
level may reveal no alterations or only minor ones; with respect to the latter alternative there may be merely a lowering in voltage that is still considered to be within normal limits.

That the triad is valid for the diagnosis of a myocardial lesion, even in the presence of a semivertical or vertical electrical position of the heart, is exemplified by our Cases 6 and 8 respectively, where at certain sequential moments, $T$ deflections at the conventional level of chest leads fell within the normal limits while $\mathrm{T}$ deflections at a higher level were decidedly abnormal.

The indication for taking special exploring chest leads, at a higher level, becomes obvious by now. They should be done when $\mathrm{T} 1$ is lower than $\mathrm{T} 3, \mathrm{~T}$ in aVL is negative, $\mathrm{T}$ in aVF is high, and when the chest leads taken at the conventional level reveal no changes or no conspicuous ones. It is furthermore obvious that these additional leads should be taken as soon as the physician has inspected the twelve leads, and preferably while the patient is still connected with the electrocardiograph. This desirable state will be much more often fulfilled in office practice with its individual approach rather than in the routine mill of hospital work where so frequently, and one may add, so unfortunately, a technical laboratory is interpolated between patient and physician. It is finally obvious that failure to take a left arm lead constitutes a regrettable omission.

\section{SUMMARY}

Nine patients who had myocardial infarctions of minor degree are presented: most probably these were small infarcts of intramural location at a high level, antero-septal-lateral. They were considered to be examples of obstructive coronary artery disease. The anginal syndrome was present in eight of the nine cases. The electrocardiographic studies revealed, in addition to T1 lower than T3, T negative in aVL and high positive in aVF, abnormalities of the T deflections (low voltage, notching, negativity) in at least several of the high chest leads, while leads taken at the conventional level exhibited either no $\mathrm{T}$-wave abnormalities or only minimal alterations. The clinical course in all these patients was benign in character.

\section{REFERENCES}

Abrahams, D. G. (1957). Brit. Heart J., 19, 232.

Alzamora, R. M., and Mispireta, A. (1948). Arch. Inst. Cardiol. Mexico, 18, 699.

Benchimol, A. B., Schlesinger, P., and Cotrim, M. R. (1947). Rev. Argent. Cardiol., 14, 369.

Breu, W. (1950). Wiener klin. Wochenschr., 62, 206.

Burch, G. W., and Ziskind, J. (1956). Editorial, Amer. Heart J., 51, 487.

Cutts, F. B., Merlino, F., and Easton, F. W. (1957). Circulation, 16, 599.

Dressler, Wm. (1943). Amer. Heart J., 26, 313.

D, and Roesler, H. (1948). Amer. Heart J., 36, 115.

East, T., and Oram, S. (1948). Brit. Heart J., 10, 263.

Evans, Wm. (1955). Brit. Heart J., 17, 55.

Goldberger, E., (1947). Amer. Heart J., 34, 395

Kubicek, F. (1958). Cardiologia, 32, 257

Moll, A., and v. Lutterotti, M. (1952). Zeitschr. Kreislauff., 41, 81.

Mussafia, A., and Comberiati, L. (1950). Cardiologia, 18, 163.

Myers, G. B., Klein, H. A., and Stofer, B. E. (1948). Amer. Heart J., 36, 535.

M, , (1949). Amer. Heart J., 37, 374.

—, and Talmers, F. N. (1955). Abstr. 28th Scientific session Amer. Heart Assoc., Circulation, $12,751$.

Papp, C., and Smith, K. S. (1951). Brit. Heart J., 13, 17.

Peluffo, G. (1951). Fol. Cardiol., 10, 273.

Prinzmetal, M., Kennamer, R., and Massumi, R. A. (1957). Circulation, 15, 575.

Pruitt, R. D., Klakeg, C. H., and Chapin, L. E. (1955). Circulation, 11, 517.

Reindell, H., and Klepzig, H. (1958). Die neuzeitlichen Brustwand-und Extremitäten-Ableitungen in der Praxis. Thieme, Stuttgart, p. 140.

Rosenbaum, F., Wilson, F. N., and Johnston, F. D. (1946). Amer. Heart J., 32, 135.

Schlant, R. C., Levine, H. D., and Bailey, C. C. (1954). Circulation, 10, 829.

Tourniaire, A., Blum, J., Guyot, R., and Dumas, J. P. (1950). Arch. Mal. Coeur, 43, 434.

Van Dooren, F., and Boyadjian, N. (1952). Cardiologia, 21, 447. 